\title{
“EU LEIO SIM": A FORMAÇÃO DO LEITOR A PARTIR DOS RESULTADOS DAS EXPERIÊNCIAS DO PIBID
}

Viviane Silva dos Santos ${ }^{\mathrm{i}}$

Gilce de Souza Almeida ${ }^{\text {ii }}$

Adriele de Jesus Oliveira ${ }^{\text {iii }}$

\section{RESUMO}

O presente trabalho tem como objetivo apresentar a contribuição das oficinas de leitura realizadas no âmbito do Programa Institucional de Bolsa de Iniciação à Docência - PIBID -, vinculado à Universidade do Estado da Bahia, como prática de incentivo à formação do leitor. As oficinas, desenvolvidas com estudantes do $6^{\circ}$ ano do Ensino Fundamental, visaram inserir no cotidiano escolar a prática da leitura como uma prioridade no processo de aprendizagem. O desenvolvimento das oficinas demonstrou que a formação do leitor não se resume à superficialidade de sugestões textuais, antes deve contar com ações pedagógicas que promovam o contato diário do educando com diversos gêneros textuais e capacitem-no para assumir o papel de copartícipe da construção dos sentidos do texto.

Palavras-chave: Texto. Leitor. Leitura. PIBID

\section{INTRODUÇÃO}

O objetivo do ensino de língua portuguesa é ampliar a competência comunicativa do aluno, para que ele esteja apto a lidar com as diversas manifestações da linguagem em seu dia-a-dia. Nesse sentido, o desenvolvimento das habilidades de leitura e escrita é o eixo fundamental para o qual devem convergir todos os esforços do professor de língua materna. É notório, porém, que, mesmo após anos de escolarização, os alunos continuam apresentando dificuldades para estabelecer relações entre as ideias de um texto, fazer inferências e produzir textos diversos.

O subprojeto "Por entre os caminhos do ensino-aprendizagem de Língua Portuguesa: da leitura à produção de texto", vinculado ao Programa Institucional de Bolsas de Iniciação à Docência (PIBID), da Universidade do Estado da Bahia (UNEB), volta seu olhar a essa realidade, propondo atividades com o objetivo de promover o desenvolvimento das habilidades de leitura e escrita no âmbito escolar. O subprojeto, que conta com 41 bolsistas de iniciação à docência, atua 
junto a cinco escolas-parceiras, municipais e estaduais, de Santo Antônio de Jesus, município localizado a 187 quilômetros de Salvador.

Neste trabalho, relataremos os impactos iniciais das atividades do subprojeto em uma turma de $6^{\circ}$ ano no que respeita às contribuições para a formação da competência leitora. Com o total de 37 alunos, a turma é composta por 20 meninos e 17 meninas, com faixa etária entre 12 e 13 anos, em sua maioria repetentes. Esse foi um dado instigante e desafiador em nossa tarefa de despertar, incentivar e promover a leitura com vista à formação do caráter do educando, ao seu desenvolvimento sociocultural e à melhor qualidade ensino-aprendizagem. Ressaltamos que as considerações apresentadas neste texto partem de resultados parciais.

As oficinas promovidas na turma têm o de intuito proporcionar aos alunos a interatividade com diferentes textos, a fim de que possam selecionar e identificar suas preferências diante do universo da leitura, construir novas possibilidades de exploração do mundo mágico das palavras e interagir socialmente.

\section{LEITOR, LEITURA E PRÁTICA}

A leitura é um processo que se dá primeiramente com a percepção e o reconhecimento dos símbolos. Posteriormente informações capitadas serão compreendidas e interpretadas. Ler não significa apenas decodificar o código linguístico, antes é uma prática em que se estabelece a relação com as impressões prévias do mundo. Ser leitor é mergulhar no universo encantador da palavra, apropriar-se desse universo e, a partir dessa experiência, estabelecer sentido(s) e ter suas expectativas de estar no mundo ampliadas.

De acordo com Sartre (1948, p. 42):

A leitura é um exercício de generosidade; e aquilo que o escritor pede ao leitor não é a aplicação de uma liberdade abstrata, mas doação de toda sua pessoa, com suas paixões, suas simpatias, seu temperamento sexual, sua escala de valores. Somente essa pessoa se entregará com generosidade; a liberdade a atravessa de lado a lado e vem transformar as massas mais obscuras da sua sensibilidade.

O leitor é, portanto, apontado como partícipe da construção do sentido do texto. Precisa doar-se integralmente ao universo criado pelo autor e assumir um papel ativo nesse "exercício de generosidade" que é a leitura. Para formar esse leitor competente que participa da significação do texto, é necessário desenvolver ações pedagógicas capazes de criar situações de leituras na sala de aula, nas quais o aluno discuta, reflita e posicione-se sobre a leitura feita, num exercício constante de interação social e construção de sua cidadania. 
Assim, entender a prática de leitura como um método de aprendizagem e crescimento intelectual é antes de tudo saber unir o útil ao agradável. Isso porque ler é um ato prazeroso que deve ser despertado logo nos primeiros anos de vida da criança, é uma prática que pode, e deve começar em casa, com a atenção e acompanhamento dos pais para que se comece a trilhar caminho de um leitor.

Entretanto, nem sempre a criança terá o devido acompanhamento para que seu gosto pela leitura seja aguçado. Há muitos desafios que vão desde a falta de atenção à falta de informação dos pais acerca da importância da leitura para seus filhos, realidade que impõe quase que exclusivamente à escola, em muitos caos, a tarefa de instruir e capacitar a criança na sua vida leitora. Cumpre lembrar o que nos diz Guedes (1999, p. 15) acerca disso: "Ler e escrever são tarefas da escola, questões para todos as áreas, uma vez que são habilidades indispensáveis para formação de um estudante, que é responsabilidade da escola.”

O professor exerce, então, um papel decisivo na formação do leitor proficiente, capaz de fazer leituras interpretativas da diversidade de textos existentes à sua volta, bem como saber identificar a funcionalidade de cada gênero textual. Cabe ao professor conduzir o ensino de leitura de forma prazerosa, distanciando-se da leitura obrigatória e sentencial feita apenas para dar respostas às atividades de interpretação de texto presentes no livro didático. Como consta dos Parâmetros Curriculares Nacionais (PCNs) de Língua Portuguesa do Ensino Fundamental:

É preciso, portanto, oferecer-lhes [aos alunos] os textos do mundo: não se formam bons leitores solicitando aos alunos que leiam apenas durante as atividades na sala de aula, apenas no livro didático, apenas porque o professor pede. Eis a primeira e talvez a mais importante estratégia didática para a prática de leitura: o trabalho com a diversidade textual. Sem ela pode-se até ensinar a ler, mas certamente não se formarão leitores competentes (BRASIL, 2000, p. 42).

Para além do contato com uma diversidade de gêneros e suportes textuais, é preciso possibilitar que os alunos levantem hipóteses a partir das pistas dadas pelo texto, confronte-as, interroguem e posicionem-se.

Nas seções a seguir, apresentaremos e discutiremos as contribuições iniciais das atividades desenvolvidas no âmbito do Projeto PIBID, para a formação da competência leitora numa turma de $6^{\circ}$ ano.

\section{METODOLOGIA}


Para o exercício do projeto, foi necessário conhecer não só o espaço físico da escola, mas, sobretudo, o perfil da turma com a qual iríamos trabalhar. Para tanto, foi aplicado o primeiro questionário/diagnóstico para a turma da $5^{\mathrm{a}}$ série/ $6^{\mathrm{o}}$ ano, a fim de coletar informações acerca da prática leitora dos discentes bem como de suas preferências de leituras. De posse dos dados coletados, pudemos desenvolver atividades coerentes com o perfil da turma.

Os primeiros encontros foram realizados na biblioteca da escola, onde foi criado um ambiente bastante receptivo, com livros dispostos nas mesas e um varal de crônicas (gênero selecionado para o trabalho com a turma). Depois de desenvolvidas atividades de sensibilização, os alunos começaram a fazer as primeiras leituras propostas pelo projeto e, então, foi criada uma ficha de controle para empréstimo e devolução dos livros da escola. Assim, era possível organizar as trocas dos exemplares entre os alunos e, sobretudo, acompanhar o andamento das leituras de cada um deles.

A partir daí, cada encontro foi dividido entre duas etapas: a primeira era reservada para os relatos de leituras voluntárias - livros que eles escolhiam na biblioteca da escola - e, a segunda etapa era destinada para o trabalho com gênero textual crônica. As oficinas tiveram também momentos de produção textual, nos quais as atividades propostas davam espaço para que os próprios alunos passassem do lugar de leitor a escritor e, dessa forma, era possível observar a construção de sentidos estabelecida pelos discentes e sua competência escrita.

\section{OS RESULTADOS INICIAIS: DESENVOLVENDO A COMPETÊNCIA LEITORA}

A partir dos primeiros dados coletados com as respostas ao questionário diagnóstico, constatamos que os estudantes compreendem a importância da leitura, uma vez que a maioria reconhecia os benefícios dessa prática para o desempenho escolar e para a sua atuação na sociedade. Entretanto, ao questionarmos sobre a frequência de visitas à biblioteca da escola, os alunos relataram que raramente frequentavam esse espaço, já que normalmente as atividades da escola limitavam-se ao espaço da sala de aula e não contemplavam um momento específico para leitura de uma obra completa. Assim, o momento de leitura estava condicionado apenas aos textos presentes no livro didático e às respostas aos exercícios propostos.

De acordo com as respostas dos alunos, a média de recomendação de leitura por unidade varia entre um a dois livros. Essa proposta, porém, não se efetivava pela troca de exemplares, leitura compartilhada, conhecimento dos autores, ida à biblioteca ou conversa sobre outras experiências leitoras. No geral, ocorria a prática de leitura e interpretação de texto promovida por atividades avaliativas ao longo das unidades. 
Ao questionarmos sobre os responsáveis pela influência ao desenvolvimento de hábitos de leitura, $60 \%$ da turma afirmaram receber incentivo na escola. 39\% mencionaram a influência direta da família e 1\% afirmou não ter incentivo de ninguém. Esses dados nos mostram que a família é pouco presente na formação do leitor e a escola ainda é o espaço que mais oferece o contato com a leitura.

Entretanto, partindo do pressuposto da aproximação com diferentes textos e em diferentes lugares, foi preciso saber quais categorias e suportes de leituras eram utilizados pelos alunos. Os textos teatral, poético e de aventura lideraram a preferência da turma. Dos suportes mais utilizados, a internet assumiu $65 \%$ do uso comum por meio da leitura de blogs, livros eletrônicos e jornais. O livro impresso representou $10 \%$ da escolha por parte dos alunos, aparecendo como coadjuvante na preferência de leitura para outros suportes como revistas e jornais.

Tendo em vistas os dados apresentados, os alunos reconheceram a necessidade e a importância da leitura e demonstraram ter a escola como entidade principal no incentivo dessa prática. Entretanto, ler ainda era um ato condicionado às atividades do livro didático e não havia o hábito de leituras mais extensas e fora da sala de aula. Assim, fez-se necessário um trabalho que despertasse o interesse pelo hábito de leitura e que oferecesse aos alunos um contato permanente com essa atividade.

Com o intuito de aproximar a turma da proposta do projeto, o primeiro gênero textual trabalhado foi crônica. Por tratar de uma narrativa curta, de caráter humorístico e com histórias típicas do cotidiano, esse gênero estava adequado às preferências da turma, a qual estava acostumada a leitura de textos curtos.

Ao longo de dois meses, com um encontro semanal com os alunos, apresentamos-lhes atividades diversas sobre o gênero em questão, possibilitando-lhe o conhecimento da estrutura desse gênero, o levantamento de hipóteses e confronto destas, a elaboração de inferências e o estímulo a formulação de opiniões em relação aos assuntos tratados. Paralelamente a essas atividades, os alunos faziam empréstimos na biblioteca, atividade que passou a acontecer fora do momento da oficina e sob a supervisão do professor.

Com o propósito de verificar os efeitos após o exercício do projeto, foi aplicado um novo questionário/diagnóstico. A partir da análise desse questionário foram constatados os primeiros indícios de mudanças. A primeira delas refere-se à rotina de leitura antes e depois das atividades do PIBID. Antes, 38\% dos alunos liam raramente os livros e, após as atividades do projeto, 50\% dos alunos passaram a ler com frequência.

Observamos também que a participação oral aumentou no decorrer das oficinas. Os alunos passaram a opinar e a perguntar com mais frequência. A concentração e o envolvimentos nas 


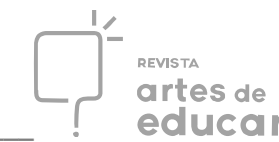

atividades passaram a ser mais perceptíveis durante os encontros, além da predisposição para leituras de livros não sugeridos durante as oficinas, ou seja, está em desenvolvimento aí uma autonomia leitora, uma vez que ler já se apresenta como uma necessidade não imposta, mas desejada - ler o que se mostrou atraente diante dos próprios olhos.

A formação do leitor envolve o processo de escrita, que é uma atividade fundamental para a vida em sociedade. Entendemos que a prática de leitura dá suporte para a construção de ideias e dessa forma o indivíduo que ler mais terá melhor desempenho nas produções de texto. Diante dessa concepção, foi questionado se contato com diferentes textos por meio da leitura despertava nos alunos a vontade de escrever histórias também. Pelas respostas dadas, constatamos que $90 \%$ mostraram-se estimulados a produzir suas próprias histórias.

Com isso, na aplicação do segundo questionário, constatamos algumas mudanças relevantes, que vão desde a participação ativa dos alunos até à produção textual mais integrada. A turma iniciou o hábito de fazer empréstimos de livros na biblioteca da escola, trocar ideias sobre o que lê e, criando histórias, passaram de leitores a escritores. Além disso, compartilhando suas impressões leitoras no momento de socialização das leituras, a oralidade foi mais exercida no contexto de opinar, criticar e descrever. Por fim, passaram a desenvolver com mais fluência a prática de identificar o próprio perfil de leitor ao informar quais eram os gêneros textuais correspondentes às suas preferências.

\section{CONSIDERAÇÕES FINAIS}

A prática de leitura deve ser exercida na escola a partir de uma metodologia dinâmica, menos sentencial e mais prazerosa, a fim de despertar o fascínio pela leitura e criação de histórias, explorar a imaginação dos alunos e conduzi-los ao fantástico universo das palavras. Contudo, no âmbito pedagógico, é certo que toda prática não se encerra nos primeiros resultados. É importante que haja a ação e a reflexão constantes para que sejam efetuadas as mudanças que são propostas e tão necessárias ao desenvolvimento do indivíduo. Essa se constitui uma das grandes contribuições deste projeto.

Além disso, o projeto fez-se importante no momento em que promoveu o diálogo entre a escola, representando a comunidade externa, e a Universidade, representada por nós, discentes em processo de iniciação às vivências da carreira docente. Esse diálogo favoreceu a escola numa perspectiva dinâmica e atrativa no que respeita ao andamento das aulas de Língua Portuguesa bem como ao desenvolvimento da turma no processo de leitura e produção de texto. 
Por outro lado, a escola como espaço real da prática de ensino, demostrada pelas experiências exercidas diante das realidades de seus alunos, estes como o sujeito principal para a execução do projeto, foi o ambiente que subsidiou as possibilidades para o exercício de ação e reflexão tão necessárias a todos docentes, a fim de promover a aplicação de práticas coerentes às teorias abordadas dentro da universidade.

\section{REFERÊNCIAS}

BRASIL. Ministério da Educação e do Desporto. Parâmetros Curriculares Nacionais: língua portuguesa. 2. ed. Brasília: Secretaria de Educação Fundamental, 2000.

GUEDES, Paulo Coimbra et al. Ler e escrever: compromisso de todas as áreas. Porto Alegre: Editora da Universidade/UFRGS, 1999, p. 15.

SARTRE, Jean-Paul. Que é a literatura? 2. ed. São Paulo: Ática, 1993.

\footnotetext{
${ }^{\mathrm{i}}$ Universidade do Estado da Bahia - UNEB

ii Universidade do Estado da Bahia - UNEB

iii Universidade do Estado da Bahia - UNEB
} 